\title{
Kyrieuon logos: Diodoro Crono y EL PROBlema DeL DETERMINISMO A LA LUZ DE METAFÍSICA IX, $3^{1}$
}

\author{
Iván de los Ríos Gutiérrez
}

\begin{abstract}
RESUMEN: El presente artículo tiene por objetivo la reconstrucción del argumento dominador (kyrieuon logos) atribuido a Diodoro Crono y su revisión filosófica a la luz de la crítica aristotélica al actualismo extremo de la Escuela de Mégara en Metafísica IX, 3. Desde esta perspectiva, el trabajo aspira a situar el proyecto teórico de Diodoro en el marco de su disputa filosófica con la metafísica aristotélica y

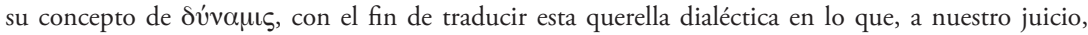
constituye una disputa teórica de importantes consecuencias prácticas: la disyunción excluyente entre el azar y el destino como paradigmas de interpretación conceptual y de acción moral.
\end{abstract}

Palabras Clave: Kyrieuon logos. Diodoro Crono. Aristóteles. Actualismo. Determinismo.

\section{INTRODUCCIÓN}

En las páginas siguientes trataremos de reconstruir la doctrina filosófica de Diodoro Crono y su célebre argumento dominador (kyrieuon logos) con el fin de valorar sus consecuencias teóricas a la luz de la crítica aristotélica al actualismo extremo de la Escuela de Mégara en Metafísica IX, 3. Nuestro objetivo es doble: por un lado, i) reivindicar un espacio reflexivo para cierto tipo de propuestas filosóficas que han sido sistemáticamente silenciadas por las líneas mayores de la historia del pensamiento occidental en general, y por la historia de la filosofía griega en particular. Y por el otro, ii) localizar la figura y el proyecto teórico de Diodoro en el marco de su disputa filosófica con la metafísica aristotélica y su concepto de potencia (dynamis), con el fin de traducir esta querella dialéctica en lo que, a nuestro juicio, constituye

\footnotetext{
${ }^{1}$ http://dx.doi.org/10.1590/S0101-31732018000100002

2 Profesor Ayudante Doctor de Filosofía en la Universidad Autónoma de Madrid (2017-), Madrid, Espańa. E-mail: ivan.delosrios@uam.es.

Doctor en Filosofía por la Universidad Autónoma de Madrid (2009). Durante los últimos cinco años ha sido Director de la Licenciatura en Filosofía de la Universidad Andrés Bello, Santiago de Chile (2012-2017). Profesor de Metafísica y Filosofía Contemporánea en la Universidad Autónoma de Madrid (2009-2012) y de Ética en la University of Loyola (2007-2012). Sus publicaciones se centran en el terreno de la filosofía antigua y en su rendimiento en el pensamiento contemporáneo.
} 
una disputa teórica de importantes consecuencias prácticas: la disyunción excluyente entre el azar y el destino como paradigmas de interpretación conceptual y de acción vital. En efecto, aquello que enfrenta en su raíz las filosofías de Diodoro y Aristóteles es la necesidad de diseñar una estructura conceptual óptima que sustente sus respectivas cosmovisiones: una realidad ya siempre constituida y abocada a un destino prefigurado, en el caso del Megárico, y una realidad abierta a la indeterminación ontológica del futuro en el del Estagirita. La de Diodoro es una propuesta determinista y necesitarista que se inserta en una cosmovisión arcaica de acuerdo con la cual todo acontecimiento significativo en la existencia de un agente racional y moral ocurriría y no podría no ocurrir, independientemente de la voluntad, el deseo y la deliberación racional de dicho agente. Nada escapa al destino, que entrega y distribuye según necesidad y justicia la parte que a cada cual corresponde. La propuesta aristotélica, en cambio, se nutre de la herencia intelectual de la ilustración ateniense y de su crítica feroz al paradigma de la religión arcaica: la realidad no puede ser reducida al marco explicativo del pensamiento religioso, esto es, a la cosmovisión trágica que identifica la totalidad de lo real con una síntesis omnímoda y clausurada en la que todo acontecimiento, por mínimo y excepcional que parezca, tiene un sentido preciso y un ajuste predeterminado desde el punto de vista de la totalidad. Ambas construcciones desembocan en dos concepciones opuestas del ejercicio práctico de la existencia humana y del sentido de la acción racional deliberada en el orden del tiempo. Pues allí donde no hay espacio para la contingencia y el azar desaparece toda elección deliberada, toda acción voluntaria y toda responsabilidad moral: volentem fata ducunt, nolentem trahunt.

\section{La Escuela de Mégara y el problema del lenguaje}

Junto con la cínica y la cirenáica, la Escuela de Mégara goza del dudoso privilegio de componer la tríada insignificante de la herencia socrática. Eso que, en clave historiográfica, conocemos como "escuelas socráticas menores" (FELIÚ, 1977). Theodor Gomperz afirma incluso que los Megáricos no son más que una suerte de neo-eleáticos (GOMPERZ, 2000, p. 181). Y lo cierto es que, mutatis mutandis, la filosofía Megárica se nos presenta como una curiosa combinación entre socratismo, eleatismo y pensamiento sofista en la que, sin embargo, destaca una profunda unidad temática en cuyo centro imperan las enseńanzas de Parménides. Desde ellas, en efecto, hemos de entender las doctrinas que los doxógrafos atribuyen al fundador de la 
Escuela Megárica, Euclides de Mégara (450-380 a.C.), cuya vida y opiniones nos transmite Diógenes Laercio en el libro II de sus Vitae philosophorum. De las diversas doctrinas atribuidas a Euclides y su escuela, nos interesa en particular la extraordinaria importancia concedida al ámbito del lenguaje y a la confrontación dialéctica:

Euclides fue natural de Megara, ciudad cercana al istmo, o según algunos, de Gela, como dice Alejandro en las Sucesiones. Estudió las obras de Parménides, y los que siguieron sus dogmas se llamaron megáricos; luego disputadores, y últimamente dialécticos. Dióles este nombre Dionisio de Cartago, porque sus discursos eran todos por preguntas y respuestas [...]. (LAERCIO, 1945, Vitae 2.106.1-6).

Hasta tal punto ese juego de preguntas y respuestas devino característico de la Escuela, que, según Laercio, Timón llegó a componer un poema en el que acusaba a Euclides de haber dado a los megarenses "[...] el rabioso furor

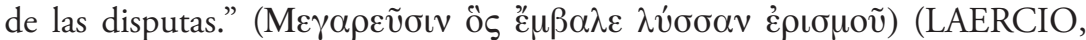
1945, Vitae 2.107.10). En efecto, la mayor parte de los Megáricos emplearon la técnica de la refutación dialéctica como plataforma de exposición de su doctrina. Euclides escribió algunos diálogos, como recuerda Diógenes, pero la tendencia generalizada de la escuela fue avanzar desde la defensa de los presupuestos lógicos y ontológicos de la metafísica parmenídea hacia un grado de sofisticación dialéctica que, en muchos casos, resulta difícil de diferenciar de los ejercicios sofísticos sobre los que nos informan Platón y Aristóteles en Eutidemo y Tópicos, respectivamente (FELIÚ, 1977, p. 49ss). Juegos dialécticos de extraordinario impacto histórico como los preferidos por Diodoro y que serán recogidos por grandes pensadores de la Antigüedad. Sexto Empírico nos recuerda el ejemplo del muro:

Si se deshace un muro ¿̇se deshace cuando los ladrillos están unidos uno a otro y ajustados, o cuando ya están separados? No se deshace el muro ni cuando están unidos a otros, ni cuando están separados; entonces, no es posible deshacer un muro. (SEXTO, Adversus mathematicos, X, 347, recogido en FELIÚ, 1977, 49ss).

Aristóteles se pregunta si "[...] el hombre que afirma estar mintiendo... ¿miente o dice la verdad? (ARISTÓTELES, Refutaciones sofísticas, 24.; cf. 25; CICERÓN, Sobre la adivinación, II, 11). Y Cicerón, por su parte, "[...] ¿cuántos granos es necesario retirar de un montón de arena para que el montón deje de existir como tal? (CICERÓN, Academica II, 49; Zenón 
de Elea, Diels-Kranz, t. 29)33. Artimañas del lenguaje, en efecto, que bien podrían servir de mero entretenimiento erístico pero que, a nuestro juicio, albergan una inmensa potencia conceptual por cuanto su objetivo parece haber sido minar la inconsistencia lógica en la que se sustentan nuestras opiniones y convicciones más sólidas acerca del mundo externo. En definitiva, una denuncia de la imposibilidad que caracteriza al pensamiento humano a la hora de captar y agotar plenamente el sentido y la estructura íntima de la realidad en su conjunto. El carácter aparentemente superficial de estas estratagemas lógicas y su naturaleza desconcertante y destructiva convirtieron a los Megáricos en fuente constante de los ataques tanto de Platón como de Aristóteles. Y, de hecho, dicha superficialidad podría conducirnos a pensar que la Escuela Megárica en nada se asemeja al pensamiento parmenídeo, como hemos afirmado al comienzo de esta exposición. Sin embargo, el talante eleático de los Megáricos debe ser rastreado más allá de las trifulcas lógicas que los caracterizaron. Ciertamente, no resulta sencillo investigar las posiciones nucleares de la Escuela de Euclides dada la naturaleza extremadamente precaria de nuestras fuentes al respecto. Por esta razón, recurriremos al debate explícito mantenido por Aristóteles con los Megáricos en Metafísica IX, 3. Ello nos permitirá mostrar que, lejos de una mera confrontación erística, lúdica o dialéctica, la controversia que se trasluce en estos escritos apunta a una determinada concepción del hombre y del mundo, así como de las relaciones epistémicas, éticas y políticas que se establecen entre ambos.

\section{KYRIEUON LOGOS: LA POLÉMICA SOBRE EL DETERMINISMO ABSOLUTO}

La polémica de Aristóteles con la Escuela Megárica se enmarca en la refutación del determinismo diseñada por el Estagirita con el fin de desacreditar toda interpretación del universo que se sirva de instrumentos mitológicos o religiosos. Cuando Aristóteles emprende la tarea de refutar el determinismo lo hace, precisamente, en la medida en que ha visto saltar a la arena filosófica un tipo de discurso que canaliza a la perfección los fundamentos de una cosmovisión arcaica y clausurada del ser que no admite espacio para la contingencia. El canal especulativo en el que se filtra esta concepción arcaica y que, a ojos de Aristóteles, hace peligrar algunos pilares básicos de la ontología crítica ilustrada como la

\footnotetext{
${ }^{3}$ En Platón (Eutidemo 299b) encontramos una variante del dilema del montón de arena en el sofisma de Dionisiodoro. Para captar el sentido de las argumentaciones megáricas, ver Aulio Gellio, Noches áticas, XVIII, 13: "[...] tú no eres lo que yo soy; yo soy un hombre, luego tú no eres un hombre." Sobre estas cuestiones, vid. Prantl (1955, p. 42-58).
} 
responsabilidad moral, la imputabilidad jurídica y la indeterminación natural, tiene el curioso nombre "argumento dominador" (kyrieuon logos) y ha sido atribuido al filósofo megárico Diodoro Crono. La figura de Diodoro constituye uno de los momentos más atractivos y, sin embargo, menos conocidos de la historia del pensamiento antiguo. De acuerdo con Laercio (1945, Vitae 2, 111 112), Diodoro era oriundo de Jaso, en el Asia Menor, a 50 kilómetros de Mileto. Aproximadamente en torno al año 350 a.C. habría llegado a Grecia con la intención de cultivarse y estudiar, adhiriéndose a la escuela Megárica fundada por Euclides y dirigida entonces por Eubulides. Se le llamó <<Crono >>, al parecer, en analogía al relato mitológico sobre el destronamiento del dios homónimo por parte de su hijo Zeus. Siendo ya anciano, Diodoro no habría sido capaz de resolver un desafío lógico propuesto por un astuto joven de la escuela Megárica, Estilpón, que con ello habría destronado a Diodoro de la posición de poder ostentada hasta entonces. No tenemos más datos de este individuo, cuya pericia lógica, sin embargo, parece haber sido absolutamente extraordinaria. Con respecto al kyrieuon, se trata de una complejísima argumentación lógica que, a grandes rasgos, afirma que nada puede suceder sino cuanto era ya siempre verdaderamente necesario que sucediera. Según Magris (1984, vol II., p. 484) y Moureau (1978, p. 348), la expresión griega puede significar algo similar a nuestro "jaque mate" en el ajedrez: un golpe de pericia contra la creencia en la libertad de elección y el concepto de posibilidad.

Las dificultades a la hora de reconstruir con cierta coherencia la doctrina del argumento dominador son notables debido a la escasez de noticias relativas al pensamiento de Diodoro. La transmisión de sus propuestas filosóficas se reduce a los escritos del propio Aristóteles, a Cicerón y Epicteto (Disertaciones por Arriano), que continúan siendo la referencia básica para la reconstrucción del argumento dominador. ${ }^{4}$ Para comprenderlo en profundidad, es necesario atender brevemente a la que constituye, sin duda, su matriz histórica y conceptual. Nos estamos refiriendo al debate entre Aristóteles y la escuela de Mégara ${ }^{5}$, donde el estagirita refuta el concepto Megárico de posibilidad en el marco de su teoría de la potencia y el acto en Metafísica IX, 3:

Hay algunos que afirman, como los megáricos, que sólo se tiene potencia para actuar cuando se actúa, y cuando no se actúa, no se tiene: por ejemplo, que el que no está construyendo no puede construir, sino sólo

\footnotetext{
${ }^{4}$ Para un intento de reconstrucción sistemática del argumento y un examen de las diversas propuestas interpretativas del mismo vid. Celluprica (1977), Giannantoni (1981), Mignucci (1966) y Vuillemin (1997).

5 Para un examen pormenorizado del mismo, vid. Magris (1976-77) y Montoneri (1984).
} 
el que está construyendo, mientras construye. Y lo mismo en los demás casos. No es difícil ver los absurdos en los que estos caen. (Metafisica IX, $3,1046 \mathrm{~b} 29-33){ }^{6}$

Como indica A. Vigo, los Megáricos estarían defendiendo, según Aristóteles, que "[...] sólo puede hablarse de la presencia de una potencia allí donde dicha potencia alcanza su realización efectiva en algún momento: no hay, pues, potencias no actualizadas, lo que equivale a decir que la potencia se reduce, en definitiva, a la actualidad." (VIGO, 2006, p. 172). Ciertamente, los conceptos de potencia y posibilidad que Aristóteles pone en boca de esta escuela resultan sorprendentes y, a primera vista, inaceptables. Sin embargo, estamos de acuerdo con Faust (1931-32, p. 30-34) en que el pensamiento arcaico que subyace a esta doctrina constituye la noción más intuitiva y, por ello, primaria de toda noción de posibilidad. De acuerdo con ella, nada puede ser dicho posible si no es verdadero afirmar de ello que es o que será. La doctrina Megárica de la posibilidad resulta inadmisible para Aristóteles por el simple hecho de que dinamita por la base la alternativa real implícita en la contingencia: la oscilación entre el ser y el no ser como posibilidad real de lo potente. Aristóteles refuta las tesis megáricas mostrando algunos de los inconvenientes o absurdos (atopa) a los que conduce su aceptación:

$[\ldots]$ ¿es que uno va a dejar de poseer el arte cuando cesa $<$ de ejercerlo $>$, pero va a ser capaz de edificar, otra vez, inmediatamente después? ¿Adquiriéndolo cómo? Y pasará igual con las cosas inanimadas. En efecto, nada habrá ni frío ni caliente ni dulce, ni nada sensible en general, a no ser que esté siendo sentido. Por consiguiente, vendrá a sostener la doctrina de Protágoras. Y ningún viviente tendrá tampoco facultad sensitiva, a no ser que esté actualmente sintiendo. Así pues, si ciego es el que no tiene vista, pero por naturaleza le corresponde tenerla, y cuando le corresponde tenerla y estando aún vivo, los mismos individuos serán ciegos y sordos muchas veces al día. (Metafísica IX, 3, 1047a3-10).

Seguidamente, rechaza la indiferenciación entre potencia y acto apelando a la evidencia de su diversidad: en efecto, la potencia y el acto son dos fases distintas de una misma realidad, de un idéntico proceso, si bien en momentos y niveles distintos:

${ }^{6}$ Todas las traducciones de Aristóteles corresponden a las versiones españolas de la editorial Gredos. 
Ahora bien, si no cabe afirmar cosas tales, es evidente que potencia y acto son distintos (aquellas doctrinas, sin embargo, identifican potencia y acto, con lo que tratan de suprimir algo de no escasa importancia) y, por tanto, cabe que algo pueda ser, pero no sea, y pueda no ser, pero sea. E igual en las demás categorías: que siendo capaz de andar, no ande, y que no esté andando, aun siendo capaz de caminar. (Metafísica IX, 3, 1047a14, cursivas nuestras)

¿Qué cosa "de no escasa importancia” suprime la concepción Megárica de la posibilidad y la potencia? Las implicaciones derivadas de la polémica aristotélica con los megáricos se encuentran a la base del argumento dominador de Diodoro Crono, que reproducimos a continuación en la versión de Epicteto (1993, 19.1.1-2.1):

El argumento Dominante parece haber sido planteado a partir de tres premisas semejantes a éstas, entre las cuales hay contradicción común y mutua; a saber: que todo pasado verdadero es necesario y que de lo posible no se sigue lo imposible y que hay posible que ni es verdadero ni lo será; y al ver esta contradicción Diodoro, se sirvió de la verosimilitud de las dos primeras para establecer que nada hay posible que no sea verdadero o que no llegue a serlo.

Hasta donde podemos reconstruirlo, el argumento se apoya en dos premisas fundamentales. 1) En primer lugar, que de todo acontecimiento pasado es verdadero decir que es necesario: $\pi \tilde{\alpha} \nu \pi \alpha \rho \varepsilon \lambda \eta \lambda v \theta$ ò $\varsigma \alpha \hat{\alpha} \eta \theta \dot{\varepsilon} \zeta$

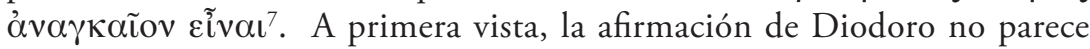
distinta de aquellas creencias populares que de Homero a Aristóteles asumen la necesidad fáctica o el principio de irrevocabilidad del pasado, esto es, que una vez acontecido, el hecho no puede no haber acontecido y es, por ende, necesario. A posteriori afirmamos, pues, la necesidad del

${ }^{7}$ La versión ciceroniana de la primera premisa reza así: omnia vera in praeteritis necesaria sunt (De fato 7.14), i.e. todo lo verdadero referente al pasado es de carácter necesario. Magris advierte un sentido confuso tanto en la versión griega como en la latina, en la medida en que ambas parecen poner el acento en la necesidad propia de los enunciados sobre hechos pasados, cuando es evidente que la necesidad de la que habla el argumento se extiende no sólo al plano formal sino, principalmente, al plano de los hechos mismos. Son los acontecimientos pasados los que aparecen como inmutables y, por ello, necesarios. Y es la necesidad del acontecimiento pasado lo que constituye el fundamento que garantiza la verdad del enunciado sobre el mismo: "En definitiva, la verdad de la proposición subsiste en la medida en que corresponde no ya a la facticidad del evento (como en Aristóteles), sino a su necesidad. Creo, por tanto, que debe leerse del siguiente modo: 'alethes esti pan pareleluthos anankaion einai'.” (MAGRIS, 1984, v. II, p. 465-466, traduccón nuestra). 
pasado, en la medida en que aquello que ha sucedido no es susceptible ya de modificación alguna, ni por intervención humana ni por intervención divina ${ }^{8}$. Ahora bien, lo que parece estar defendiendo Diodoro no es sin más la necesidad retrospectiva de lo que ha llegado a ser, sino su necesidad absoluta, pues, en efecto, no dice que lo pasado sea necesario una vez pasado, sino, más bien, que "es verdadero que lo pasado es necesario". Imaginemos un acontecimiento cualquiera como, por ejemplo, la lectura de una tesis doctoral. Imaginemos que dicho acontecimiento ya ha tenido lugar y que nos disponemos a dialogar sobre el asunto. Diremos la verdad si, una vez acontecida la lectura de la tesis, afirmamos: "la lectura de la tesis ha tenido lugar", "hoy se ha realizado una lectura de tesis doctoral", etc... Diremos lo falso, en cambio, si afirmamos de ese hecho que no ha acontecido, siendo el caso que sí ha acontecido. El problema que asoma tras estas consideraciones cuasi banales es el mismo que ocupará a Aristóteles en los conocidos pasajes del De interpretatione, a saber: ¿se reduce la verdad de la afirmación a la facticidad del acontecimiento y a la coincidencia circunstancial entre el enunciado y el hecho? ¿No es la verdad un valor absoluto al margen de circunstancias ocasionales? La verdad de lo verdadero, en definitiva, ¿no es siempre y necesariamente válida? Si respondemos afirmativamente a esta cuestión, hemos de aceptar, entonces, la siguiente conclusión: "hoy ha tenido lugar una lectura de tesis doctoral" es verdadero una vez leída la tesis doctoral, pero, en cuanto tal, era ya verdadero incluso meses antes de que dicha lectura se produjera en acto. Era ya siempre y necesariamente verdadero. La necesidad del acontecimiento ya sucedido no se reduce, por tanto, al hecho circunstancial de su ser el caso, sino que se retrotrae a la esfera atemporal de la verdad misma. De modo que la verdad de la proposición que afirma "se ha producido una lectura de tesis doctoral" implica que dicho acontecimiento estuviera ya desde siempre predeterminado y fuera, por tanto, necesario incluso antes de emerger al ser, a la apariencia y al discurso. Si, por el contrario, respondemos negativamente, tendremos que aceptar que lo verdadero y lo falso son intercambiables y que transitan sin dificultad del uno al otro. Esta es la tesis fuerte de Diodoro. En efecto, si la afirmación "hoy se ha realizado una lectura de tesis doctoral" es verdadera sólo hoy, es decir, después de haber sido realizada, entonces ello

\footnotetext{
8 Se trata del famoso factum infectum fieri nequit que encontramos ya en Ilíada: Néstor, a la vista de los acontecimientos desgraciados para los aqueos, afirma "Es verdad que los hechos están patentes, y ni siquiera el propio Zeus altitonante puede imaginar algo para mudarlos." (Il. XIV, 53-54 (trad. E. Crespo); PLATÓN, Protagoras 324 b; ARISTÓTELES, De interpretatione IX y XIII).
} 
quiere decir que dicha con anterioridad al momento en que el evento se produce, no era una frase verdadera sino necesariamente falsa, pues una tercera posibilidad no es admisible (tertium non datur) (Metafísica IV, 7). El principio del tercio excluso constituye un verdadero problema para la crítica del determinismo y Diodoro es perfectamente consciente de ello. En Metafísica IV, 7, Aristóteles nos dice:

Por otra parte, tampoco puede darse un término intermedio entre los contradictorios, sino que necesariamente se ha de afirmar o negar uno de ellos, sea el que sea, de una misma cosa. $<1>$ Ello resulta evidente, en primer lugar, con sólo definir previamente qué es lo verdadero y lo falso. Falso es, en efecto, decir que lo que es, no es, y que lo que no es, es; verdadero, que lo que es, es, y lo que no es, no es. Por consiguiente, quien diga que <algo> es o no es, dirá algo verdadero o algo falso. Sin embargo, ni de lo que es ni de lo que no es puede decirse <indistintamente> que es o que no es. (Metafisica IV, 7, 1011b23-29).

Como recuerda J. Vuillemin en un trabajo esencial para el problema que nos ocupa (VUILLEMIN 1979, p. 225-257; VUILLEMIN 1984), la primera premisa del kyrieuon parece tener en consideración no solo el principio del tercio excluso, sino también las tesis antimegáricas del Aristóteles en Metafísica IX, 3 y algunas afirmaciones contenidas en escritos precedentes, como De caelo I, 11, 280b13, donde Aristóteles afirma que lo imposible es aquello de lo que no es verdadero decir que podrá ser o que se generará y lo posible aquello de lo que es verdadero afirmar que será. ${ }^{9}$ Tomando en consideración estas afirmaciones - distintas, por lo demás, de Metafísica IX, 3 - y asumiendo el principio del tercio excluso, las tesis de Diodoro parecen simplemente irrefutables: si aceptamos que toda proposición es verdadera o falsa y si es verdadero que todo acontecimiento pasado es necesario, entonces podemos concluir que los eventos sucedidos eran necesarios incluso antes de venir a la existencia. Es decir, que era verdadero decir de ellos que sucederían antes de que sucedieran, y falso decir lo contrario. Por ello mismo, podemos concluir también que de todo acontecimiento que no se ha realizado en el tiempo era verdadero afirmar que era imposible que sucediera, y falso afirmar que era posible. Posible es lo que necesariamente sucede o sucederá.

9 "Lo imposible, por su parte, se define de dos maneras. O bien porque no es verdad si uno dice que algo se generará, o bien porque no se genera con facilidad, rapidez ni perfección." (DC I, 11, 280b1214). "En otro sentido, si una cosa es posible, definiéndose lo posible bien <en el sentido de poder llegar a ser> verdaderamente bien fácilmente." (I, 11, 280 b16-18). 
2) La segunda premisa del argumento dominador es la siguiente:

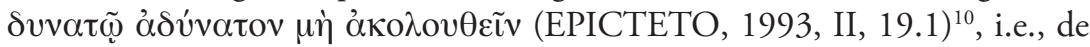
lo posible no se sigue lo imposible. El eco de la polémica aristotélica con las tesis Megáricas es evidente. En su interior, como vimos más arriba, Aristóteles defendía la posibilidad de que "[...] algo pueda ser pero no sea, y pueda no ser, pero sea." (Metafísica IX, 3, 1047a21-22). De manera que si afirmamos "es posible que hoy nieve" o "es posible que Juan llame por teléfono", estamos simultáneamente afirmando que también es posible que no nieve y que Juan, finalmente, no llame por teléfono. Ahora bien, según la perspectiva de Diodoro, si afirmamos la posibilidad de un hecho y ese hecho no acontece, entonces la posibilidad se convierte inmediatamente en imposibilidad, pues lo posible es aquello que es o que será necesariamente, como vimos más arriba. En efecto, si afirmo que "es posible que Juan llame hoy por teléfono" y pasado el día Juan no ha llamado, la posibilidad de que Juan llame queda completamente anulada, se convierte en algo imposible: no era verdadero afirmar la posibilidad de la llamada, esto es, era falso decir "es posible que Juan llame hoy por teléfono" si es cierto que toda proposición es verdadera o falsa y que no hay una tercera alternativa. Pues, de haber sido verdadera la proposición, habría sido ya siempre verdadera y, por ende, el acontecimiento anunciado por ella habría acontecido necesariamente. Lo posible verdadero, por tanto, es aquello que desde siempre es posible y, en cuanto tal, aquello que necesariamente vendrá a la existencia. Al contrario, lo imposible verdadero es aquello que ya siempre ha sido y será imposible, i.e., aquello que necesariamente no vendrá a la existencia.

A diferencia de la primera de las premisas - orientada retrospectivamente al pasado y a la necesidad de los acontecimientos que lo pueblan - la segunda proposición del argumento se distingue por su naturaleza prospectiva. Las tesis diodorianas se abren al debate sobre la determinación o indeterminación del futuro. En efecto, la pregunta que nos sale al paso es la misma que habrá de afrontar Aristóteles: ¿qué podemos saber del futuro? ¿Qué podemos decir con verdad del futuro? De aquello que está por venir podemos afirmar que es posible, que su existencia se mueve para nosotros en el terreno de la incertidumbre, en la niebla de aquello que no nos ha sido dado conocer. El ser humano se caracteriza por su incapacidad para saber con certeza lo que ocurrirá mańana. $\mathrm{Y}$ es la ignorancia y la tensión de esa espera lo que nos impulsa a construir

${ }^{10}$ Cicerón no se mantiene fiel al texto de Epicteto y desplaza el nivel ontológico del binomio posibleimposible al plano lógico-formal del verdadero-falso. A su juicio, el argumento afirma que no es posible convertir la verdad en falsedad: in falsum e vero praeterita non possunt convertere (De fato 7.14): “[...] lo pasado no puede pasar de lo verdadero a lo falso." 
nuestra propia existencia como un proyecto flexible hacia un futuro en el que todo parece posible. En tanto animales, como recuerda Aristóteles, que gozan de cierta conciencia del tiempo (De anima III 10, 433b6-7), lo cual les permite estar ya siempre "lanzados más allá de toda situación particular de acción, en dirección de un horizonte futuro de posibilidades, a partir del cual deben intentar apropiarse significativamente de la situación presente en cada caso." (VIGO, 2006, p. 186). En la interpretación del horizonte en el que se despliega la perspectiva futura y en la lectura exacta de la incertidumbre se juegan dos propuestas de sentido plenamente antagónicas: aquella que responde a la imagen arcaica del mundo - que una ontología de corte parmenídeo conserva y apuntala con su potencia lógica - y aquella otra, la ilustrada, que rompe definitivamente con una imagen del ser y el tiempo en la que todo queda incluido, localizado y condenado a la clausura perpetua de la necesidad y la predeterminación. El argumento dominador de Diodoro es deudor tanto de la cosmovisión arcaica como de la ontología parmenídea. Por ello, la respuesta que el filósofo Megárico puede dar a la pregunta sobre el futuro se presenta con radicalidad y crudeza. Insistamos en ese interrogante: ¿qué podemos saber con verdad acerca del futuro? Que se abre ante nosotros y que es posible, respondimos más arriba. La cuestión que interesa a Diodoro una vez aceptada esta respuesta es la siguiente: ¿es verdadero que el futuro es posible? La verdad de esta afirmación estará garantizada si y sólo si el evento futuro sobre el que hablamos - "mañana nevará" - pertenece no ya al ámbito de la indeterminación, sino al de la más absoluta necesidad. Es verdadero que el futuro es posible y es verdadero decir "es posible que mañana nieve" si y sólo si el futuro en general y el evento "nevada" en particular son necesarios, es decir, si no pueden no acontecer. De hecho, si afirmo que es verdadero decir "es posible que mańana nieve" y mańana, de hecho, no nieva, la verdad de la proposición se convertirá automáticamente en falsedad, del mismo modo que la posibilidad ontológica habrá pasado a imposibilidad pura. La posibilidad enunciada resulta, por tanto, imposible y, además, falsa, pues no era verdad decir que era posible aquello que se ha mostrado como imposible. Diodoro está fundamentando la verdad de las proposiciones sobre el futuro posible en la necesidad de todo acontecer. Siempre que se produzca un evento que considerábamos posible hemos de concluir que dicho evento no podía no haber sido el caso. Al contrario, siempre que un evento que creíamos posible no viene a la existencia, hemos de concluir que dicho evento en realidad era imposible y que era verdadero afirmar del mismo que era imposible. Pues la verdad de toda proposición implica la necesidad, la inmutabilidad y la eternidad de aquello sobre lo que es afirmada. 
En conclusión, podemos resumir el argumento maestro de Diodoro Crono del modo siguiente:

1) el pasado es verdadero porque es necesario

2) lo posible, si es verdaderamente posible, no puede convertirse en imposible, dado que lo verdadero no puede convertirse en falso

3) por tanto, el futuro posible es verdadero si necesariamente es o será, mientras que es falso si necesariamente no es y no será.

Como puede apreciarse, el argumento dominador se sustenta sobre una elegante pericia lógica y dialéctica. Sin embargo, su potencia - aniquiladora, en muchos casos - no debe ser simplificada. Es decir, no hemos de cometer el error de reducir la complejidad y la riqueza especulativa de los problemas que aquí se anuncian diciendo que la escuela Megárica no pretendía sino ejercitar sus habilidades dialécticas y, a lo sumo, hacer tambalearse los cimientos del sentido común y de las propuestas filosóficas vigentes. De ser este el caso, ¿por qué no tratar de dinamitar también, por ejemplo, la lógica del ser parmenídeo? En este sentido, compartimos las posiciones de Schuhl (1960, p. 15), Faust (1931-32, p. 37-40), Becker (1956, p. 289-304) y Magris (1984, p. 470) que ven en el argumento dominador una expresión contundente de la ontología parmenídea y de una determinada concepción global de la totalidad del ser: aquello que está en juego en la argumentación diodoriana es el modo de comprender el sentido de lo que acontece y, por ende, las relaciones entre la acción racional, la existencia temporal del ser humano y la totalidad que lo contiene. Diodoro parece suscribir una cosmovisión arcaica que concibe la realidad como una unidad sintética y ya siempre clausurada que va apareciendo y desvelándose necesariamente en el tiempo ante la mirada de los hombres, quienes, ignorantes, no pueden sino tratar elaborar estrategias de interpretación de lo que ocurre:

De este modo, el argumento dominador nos enseña que no existen argumentos contra el destino: todo cuanto sucede, si sucede, estaba destinado a suceder, y si no sucede, estaba destinado a no suceder por el mismo motivo. El futuro no es un vacío que haya que rellenar de cualquier modo, sino parte integrante del círculo en el que el tiempo, de acuerdo con el destino, hace aparecer la totalidad ya siempre completada del ser, una totalidad que el saber humano en su finitud no puede más que reconstruir. (MAGRIS, 1984, p. 470, traducción nuestra). 
Magris muestra una extrema elegancia en su exposición, como de costumbre, pero se equivoca en un punto importante. Diodoro parece enseñarnos que no existen argumentos de fondo en contra de la necesidad de todo lo que acontece, pero lo hace, precisamente, porque sabe que de hecho existen argumentos contra el destino y que tales argumentos son, sin ir más lejos, los de Aristóteles. Ahora bien, tales argumentos no descansan en el ejercicio lúdico de las habilidades dialécticas del Estagirita. Aristóteles combate - aunque sin mencionarlo - el argumento de Diodoro no en cuanto constructo lógico atractivo y desafiante, sino en cuanto verdadera amenaza a algunos de los presupuestos fundamentales de su filosofía. En concreto, la contingencia, la libertad y el azar o, en otras palabras, la posibilidad de la elección deliberada, la acción voluntaria, la responsabilidad moral y la imputabilidad jurídica en un horizonte temporal abierto a la indeterminación del futuro y, por tanto, a la libre configuración de la propia existencia en el seno de una comunidad política. La presentación que hemos hecho del argumento dominador quiere contribuir al debate aristotélico sobre la contingencia del universo natural. En este sentido, no nos interesan tanto las consideraciones lógicas ${ }^{11}$ del kyrieuon como sus implicaciones doctrinales y su pertenencia a un determinado debate vigente en la época de Diodoro y Aristóteles, a saber: el debate en torno a la disyuntiva excluyente entre el azar y el destino, i.e., el debate en torno a la libertad moral del agente racional en un contexto ya siempre predeterminado o en un universo abierto a la indeterminación del porvenir y a la acción técnica y racional del hombre.

\section{A MOdo DE CONCLUSIÓN: ARISTÓTELES Y EL NECESITARISMO}

Los argumentos aristotélicos en favor de la contingencia y contra el necesitarismo, el determinismo y el destino los encontramos en un escrito de extraordinaria repercusión histórica: De interpretatione ${ }^{12}$. En el capítulo 9, Aristóteles acomete la tarea de investigar el valor de verdad de las proposiciones referidas a futuros contingentes y el sentido específico en que debemos entender el principio de tercio excluso aplicado a los mismos:

\footnotetext{
${ }^{11}$ Para un enfoque preeminente lógico-formal del argumento dominador, vid. M. Boudot (1973, 1983), Moureau (1978), Prior (1953, 1955).

${ }^{12}$ Se trata, en efecto, del pasaje del corpus aristotelicum sobre el que probablemente más páginas se han escrito. El estudio más completo continua siendo con toda probabilidad el de Dorothea Frede (1970), si bien cabe recordar otros trabajos relevantes como los de Anscombe (1967), Bradley (1959), Buttler (1955) y Gaskin (1995), entre muchos otros.
} 
Así pues, en las cosas que son y que fueron, es necesario que o la afirmación o la negación sea verdadera o falsa [...] En cambio, con los singulares futuros no <ocurre $>$ igual. En efecto, si toda afirmación o negación $<\mathrm{es}>\mathrm{o}$ verdadera o falsa, también necesariamente todo <lo afirmado o negado $>$ ha de darse o no darse; pues si uno dijera que algo será y otro dijera que eso mismo no será, es evidente que uno de los dos dice necesariamente la verdad, si toda afirmación es verdadera o falsa: pues en las cosas de este tipo no se dará ambas a la vez. En efecto, si es verdad decir que es blanco o que no es blanco, necesariamente será blanco o no será blanco y, si es blanco o no es blanco, será verdad afirmarlo o negarlo; $y$, si no se da, se dice una falsedad y, si se dice una falsedad, no se da; así que necesariamente la afirmación o la negación ha de ser verdadera. (De interpretatione, 9, 18a28-b4).

El nombre de Diodoro Crono no aparece en ningún momento del texto, pero sus tesis están sin duda en la mente del Estagirita cuando dicta estas líneas. En ellas, en efecto, encontramos una cierta identificación de la noción de verdad con la idea de ser o existencia, que lleva a afirmar que toda proposición verdadera sobre un acontecimiento pasado, presente o futuro, implica de suyo la necesaria existencia de dicho acontecimiento. Si aceptamos esta primera conclusión y tenemos en cuenta el principio de tercio excluso, una de las siguientes proposiciones, en cuanto opuestas, será necesariamente verdadera: "mañana nevará" / "mañana no nevará". Por tanto, necesariamente nevará o necesariamente no nevará, y una tercera opción es inaceptable. Si nieva, entonces la posibilidad de que nevara y el hecho actual de la nevada coinciden en la necesidad que los subyace, pues lo posible no es sino aquello que necesariamente es o será. Si no nieva, entonces es que era imposible que nevara y era verdadero decir que era imposible que nevara, del mismo modo que era falso decir que nevaría. La posibilidad, en fin, se identifica con la necesidad de que acontezca aquello que no puede sino acontecer, pues lo posible no puede transformarse y mutar en lo imposible si es verdaderamente posible. Contra estas argumentaciones, Aristóteles se limita a mostrar los absurdos derivados de la aceptación de sus premisas. Y es importante para nosotros resaltar cuáles son los dos absurdos principales que, a ojos del macedonio, se derivan de dichas posiciones: en primer lugar, i) la negación de la contingencia y el azar; y en segundo lugar, ii) la negación de la elección voluntaria, de la responsabilidad moral y de la imputabilidad jurídica. Con respecto al problema del azar y la contingencia, el Estagirita declara:

Ahora bien, entonces nada llega a ser por azar ni llega a ser cualquier cosa al azar, ni será o no será, sino que todas las cosas son lo que son por necesidad y 
no cualquier cosa al azar (en efecto, o bien dice la verdad el que afirma o bien el que niega); pues < de otro modo> lo mismo podría llegar a ser que no llegar a ser; en efecto, lo que llega a ser cualquier cosa al azar no tiene ni tendrá por qué ser así o no ser así. Además, si es blanco ahora, era verdad antes decir que sería blanco, de modo que siempre era verdad decir, de cualquiera de las dos cosas que llegaron a ser, que sería; y si siempre era verdad decir que es o que será, no es posible que tal cosa no sea ni vaya a ser. Ahora bien, lo que no es posible que no llegue a ser es imposible que no llegue a ser; y lo que es imposible que no llegue a ser, es necesario que llegue a ser; así pues, todo lo que será es necesario que llegue a ser. Ahora bien, no será en absoluto cualquier cosa al azar ni será por azar; pues si < fuera > por azar, no <sería > por necesidad. (De interpretatione, 9, 18b5-16).

Si todo suceso acontece porque era posible y necesario que aconteciese, entonces nada se producirá de modo indeterminado y fortuito, no existirá ninguna excepción posible al modo en que necesariamente se desenvuelven todas las cosas. Pues, en efecto, lo que es no podía no ser, no albergaba en sí mismo la disponibilidad tanto para el ser como para el no ser que abre espacio para el acontecimiento excepcional y el acaecer accidental. El empleo que Aristóteles está haciendo en estas líneas de la expresiones apo tyches y hopoter etychen alude al margen de indeterminación inscrito en la composición matérica del univeso natural, a la contingencia que hace posible que algunos acontecimientos sucedan de modo distinto a como suelen suceder, o que aquellos acontecimientos que suelen ser el caso, debido a circunstancias ocasionales, no vengan a la existencia. Como ha escrito Quevedo (1989, p. 413):

En la raíz de la indeterminación gnoseológica se sitúa una auténtica indeterminación ontológica, que es fundamento de aquella y que no puede ser reducida a simple indeterminación cognoscitiva. El Estagirita nos previene aquí de un riesgo que acecha a todos los filósofos: el de reducir la indeterminación ontológica a la indeterminación meramente gnoseológica, en aras de salvaguardar la total determinación de lo real y su consiguiente racionalidad. El azar y la indeterminación son reales; no son máscaras para encubrir nuestra ignorancia, ni paliativos gnoseológicos de un determinismo ontológico sin fisuras. La concepción del azar como idea puramente subjetiva no puede ser reconciliada con lo que se dice en De interpretatione 9. Lo que Aristóteles deja sentado en este lugar no es la imposibilidad de saber si una proposición de futuro contingente es verdadera o falsa, sino la imposibilidad de que tal proposición sea, o bien verdadera, o bien falsa. 
Si lo posible no puede no ser sino sólo y necesariamente actualizarse, entonces no queda espacio para la aparición de lo excepcional, pues todo se comporta inevitablemente como debe comportarse, sin posibilidad de alteración. De todo ello se derivaría el segundo de los absurdos del que hablaba Aristóteles: la eliminación de la libertad de elección en una acción voluntaria y, por tanto, la desactivación de toda responsabilidad moral e imputabilidad jurídica, así como de toda posibilidad real de autoconfiguración responsable de la propia vida: en efecto, si todo cuanto acontece en el orden del ser no podía no acontecer, entonces el hombre no hace sino lo que necesariamente tenía que hacer. La posibilidad de elegir entre cursos de acción opuestos, entre resultados contrarios, la alternativa, en fin, en que consiste la ejecución de un acto deliberado y libre, se difumina en un único flujo de causación predeterminada:

Estos y otros por el estilo <son>, entonces, los absurdos que resultan si es necesario que, de toda afirmación y negación opuestas, ya <versen $>$ sobre los universales enunciados como universales, ya sobre los singulares, la una sea verdadera y la otra falsa, y que nada de lo que sucede sea cualquier cosa al azar, sino que todo sea y suceda por necesidad. De modo que ni sería preciso deliberar ni preocuparse, <pensando $>$ que, si hacemos tal cosa, se dará tal otra y, si no, no se dará. En efecto, nada impide que uno diga para dentro de diez mil ańos que habrá esto y que otro diga que no, de modo que necesariamente será cualquiera de las dos cosas que en aquel momento era verdad decir <que sería>. Pero, desde luego, eso no difiere de si algunos dijeron o no la contradicción, pues es evidente que las cosas reales se comportan así aunque no haya quien afirme ni quien niegue; en efecto, <las cosas> o serán o no serán no por afirmarlas o negarlas, ni dentro de diez mil años más que dentro de cualquier otro tiempo. De modo que, si en todo tiempo se comportan las cosas de tal modo que uno de los dos dice la verdad, sería necesario que sucediera eso o lo otro, y que cada una de las cosas que llegan a ser se comportara de tal modo que llega a ser por necesidad: pues lo que se dijera con verdad que había de ser no podría no llegar a ser; y lo que llegara a ser siempre sería verdad decir que había de ser. (De interpretatione 9, 18b26-19a4).

Aquello que parece inquietar a Aristóteles en su refutación del kyrieuon son sus implicaciones demoledoras en el terreno de la praxis: si el ser humano no es libre de hacer lo que hace, ¿para qué actuar? ¿Por qué preocuparnos en conducir nuestras vidas de un modo mejor que de otro? ¿Por qué comportarnos moralmente? ¿En base a qué criterios se premiarán o castigarán nuestros actos? Comentaristas antiguos del De interpretatione como Amonio (1897, p. 147-148) se apercibieron de la relevancia ética de 
una refutación de Diodoro. En cualquier caso, las consecuencias para la ética no son el único argumento en defensa de la contingencia. ¿Cuáles son los otros argumentos aristotélicos contra el necesitarismo lógico, ontológico y ético? La respuesta aristotélica se construye en los pasajes siguientes apelando al famoso ejemplo de la batalla naval, sobre el que se han derramado ríos de tinta (FREDE, 1970, 1972). Aristóteles se dispone a apuntalar su posición frente al absurdo necesitarista mediante una especificación del principio del tercio excluso. Para ello, negará que todas las proposiciones asertivas sobre acontecimientos singulares tengan valor de verdad. Tan sólo aquellas referidas al pasado lo tienen - la necesidad de lo acontecido es, desde luego, irrefutable: factum infectum fieri nequit: "Así pues, es necesario que lo que es, cuando es, sea, y que lo que no es, cuando no es, no sea." (De interpretatione 9, 19a23-24). Las relativas al futuro, en cambio, carecen de valor de verdad, no pueden ser ni verdaderas ni falsas, pues la verdad de un enunciado se deriva de la adecuación del mismo a la determinación de un acontecimiento o hecho, afirmando que es, cuando es, y afirmando que no es, cuando no es. Ahora bien, dado que la ontología aristotélica asume la contingencia del universo natural, el futuro se perfila como horizonte abierto e indeterminado. Por ello no es posible que las proposiciones sobre futuros contingentes puedan ser verdaderas o falsas: "[...] no es necesario ni que todo lo que es sea ni que todo lo que no es no sea: pues no es lo mismo que todo lo que es, cuando es, sea necesariamente, y el ser por necesidad sin más; de manera semejante también en el caso de lo que no es." (De interpretatione 9, 19a24-27).

Partiendo de estas premisas, Aristóteles especifica el principio según el cual toda proposición es verdadera o falsa recurriendo al ejemplo de la batalla naval:

Digo, por ejemplo, que, necesariamente, mañana habrá o no habrá una batalla naval, pero no que sea necesario que mańana se produzca una batalla naval ni que sea necesario que no se produzca; sin embargo, es necesario que se produzca o no se produzca. (De interpretatione 9, 19a29-32).

La posibilidad de la batalla queda arrinconada en la alternativa entre dos opciones contradictorias. Dicha alternativa es aquello que Aristóteles retiene como absolutamente necesario, pues, en efecto, la verdad de uno de los dos términos de la oposición excluye la verdad del otro y un tercero no es concebible. Ahora bien, que necesariamente se produzca o no una batalla 
en la jornada de mañana no convierte a la actualización de una de las dos posibilidades en un suceso ineluctable, pues dado que la necesidad descansa en la disyunción y en la alternativa, cada una de las dos posibilidades conserva su estatuto de contingencia. En otras palabras: es posible que mañana haya una batalla naval y es posible que no la haya; es necesario, en cambio, que una de las dos cosas ocurra, si bien aquella que ocurra no ocurrirá por necesidad, sino por otras causas - la decisión de ambos almirantes de poner en marcha la contienda, por ejemplo, siendo posible también que ambos hubieran decidido postergarla, o que una terrible tormenta les hubiera obligado a ello. En definitiva, es imposible saber con anterioridad lo que ocurrirá en el porvenir y no será verdadero decir de un acontecimiento futuro contingente que ocurrirá hasta el momento en que haya ocurrido. Imposible porque el territorio al que dicha batalla hipotética pertenece -el futuro- aparece para Aristóteles como espacio de indeterminación, como proyección realizable mas no realizada aún que testimonia el carácter progresivo y constructivo del devenir, abierto siempre a la indeterminación, la excepción y la acción racional.

La propuesta de Aristóteles ha sido objeto de múltiples estudios, principalmente en el ámbito del pensamiento lógico y la filosofía analítica contemporánea ${ }^{13}$. No daremos cuenta de la polémica en estas páginas. Por lo que respecta al interés central que subyace a este trabajo, Aristóteles, al criticar las tesis centrales de Diodoro Crono, ejecuta una refutación del determinismo absolutamente crucial para la fijación conceptual de la contingencia y el azar. Y ello porque sólo es posible habilitar un espacio reflexivo para los acontecimientos fortuitos allí donde ha sido abolido el determinismo absoluto. Es decir, allí donde se ha roto definitivamente con la cosmovisión arcaica del ser como una totalidad ya siempre constituida en cuyo seno todos y cada uno de los sucesos son expresión inevitable del conjunto: allí donde el ser, en definitiva, no es el desvelamiento inviolable del destino que todo lo abraza, sino la configuración progresiva, ordenada y contingente de una realidad en construcción transida de libertad, azar e indeterminación. La propuesta filosófica de Diodoro, lejos de constituir un mero artificio lógico y dialéctico, desafía en sus planteamientos nuestras convicciones más cotidianas, y contra ese desafío pretende blindarnos precisamente la doctrina de Aristóteles

${ }^{13}$ Para un informe detallado del estado de la cuestión hasta principios de los años 80, Celluprica (1977). Para una bibliografía más reciente, consultar Quevedo (1989, p. 410 y ss). 
RÍOS GUTIÉRREZ, I. KYRIEUON LOGOS: Diodorus Chronus and the problem of determinism in the light of Metaphysics IX, 3. Trans/form/ação, Marília, v. 41, n. 1, p. 9-30, Jan./Mar., 2018.

ABstract: This paper aims to reconstruct and analyze the Master Argument (kyrieuon logos) attributed to Diodorus Chronus under the perspective of Aristotle's criticism of extreme actualism in Metaphysics IX. 3. From this point of view, the paper locates Diodorus' theoretical project within the framework

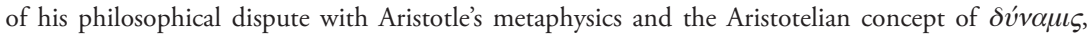
trying to show that what really lies behind this dialectical confrontation is a theoretical problem of important practical consequences: the excluding disjunction between chance and destiny as paradigms of conceptual interpretation and moral action.

KeYwords: Kyrieuon logos, Diodorus Chronus, Aristotle, Actualism, Determinism.

\section{Bibliografía}

AA:VV. Studi sulla dialettica. Turín: Taylor, 1969.

AMONIO. Ammonius in Aristotelis de interpretatione commentarius. In: BUSSE, A. (Ed.). Commentaria in Aristotelem Graeca 4.5. Reimer: Berlin, 1897.

ANSCOMBE, G. E. M. Aristotle and the sea battle: de interpretatione IX. In: MORAVCSIK, J. M. E. (Ed.). Aristotle. Doubleday: Garden City, N.Y., 1967. p. 15-33.

ARISTÓTELES. Metafísica. Gredos: Madrid, 1998.

. Refutaciones sofísticas. In: Tratados de lógica (Organon, v. I). Gredos:

Madrid, 1982.

. Sobre la interpretación. In: Tratados de Lógica (Organon, v. II). Gredos:

Madrid, 1988.

. Acerca del cielo. Gredos: Madrid, 1996.

BECKER, O. Über den "Kyrieuon Logos” des Diodorus Kronos. Rheinisches Museum, v. 99, p. 289-304, 1956.

BOUDOT, M. Temps, nécessité et prédétermination. Les Etudes Philosophiques, v. 4, p. 435-473, 1973.

. L'argument dominateur et le temps cyclique. Les Etudes Philosophiques, n. 3, p. 271-298, Jul/Sep. 1983.

BRADLEY, R. D. Must the future be what it is going to be? Mind, v. 68, n. 270, p. 193209, 1959.

BRUNSCHWIG, J. (Ed.). Les stoiciens et leur logique. Paris: Vrin, 1978. 
BUTTLER, R. J. Aristotle's sea fight and threevalued logic. Philosophical Review, v. 64, n. 2, p. 264-274, 1955.

CELLUPRICA, V. L'argomento dominatore di Diodoro Crono e il concetto di possibile di Crisippo. In: GIANANNTONI, G. Scuole socratiche minori e filosofia ellenistica. Bologna : Centro di Studio per la Storia della Storiografia, 1977. p. 55-73.

DIÓGENES LAERCIO. Vidas de los filósofos ilustres. Buenos Aires: Emecé, 1945.

EPICTETO. Disertaciones por Arriano. Madrid: Gredos, 1993.

FAUST, A. Der Möglichkeitsgedanke: systemgeschichtliche Untersuchungen, II v. Heidelberg: Winter, 1931-1932.

FELIÚ, S. Socráticos menores (cínicos, cirenáicos y megáricos). Valencia: Departamento de Filosofía de la Universidad de Valencia, 1977.

FREDE, D. Aristoteles und die Seeschlacht: das Problem der "Contingentia Futura" in De interpretatione 9. Göttingen: Vandehoeck und Ruprecht, 1970.

GASKIN, R. The Sea Battle and the Master Argument: Aristotle and Diodorus Cronus on the metaphysics of the future. Berlin-N.Y.: De Gruyter, 1995.

GIANANNTONI, G. Scuole socratiche minori e filosofia ellenistica. Bologna: Centro di Studio per la Storia della Storiografia, 1977.

. Il kyrieuon logos di Diodoro Crono. Elencos, v. 2, p. 239-272, 1981.

GOMPERZ, T. Pensadores griegos. III v. Barcelona: Herder, 2000.

HOMERO. Ilíada. Madrid: Gredos, 1994.

MAGRIS, A. L'idea di destino nel pensiero antico. II v. Udine: Del Bianco, 1984.

. Aristotele e i Megarici: contributo alla storia del determinismo antico. In: Atti

Dell'Accademia Delle Scienze di Torino: Classe di Scienze Morali, Storiche e Filologiche, v. 111, p.113-133, 1976/1977.

MIGNUCCI, M. L'argomento dominatore e la teoria dell'implicazione in Diodoro Crono. Vichiana, v. 1, p. 3-28, 1966.

MONTONERI, L. I Megarici: studio storicocritico e traduzione delle testimonianze antiche. Catania: Grafica del Libro, 1984.

MOUREAU, J. L'innmutabilité du vrai. In: BRUNSCHWIG, J. (Ed.). Les stoiciens et leur logique. Paris: Vrin, 1978.

PRANTL, C. Geschichte der Logik im Abendlande. Reimpr. Gräz, Austria: Akademische Druck-u ; Verlagsanstalt, 1955.

PRIOR, A N. Three-valued logic and future contingents. Philosophical Quarterly, v. 3, n. 13, p. 317-26, 1953.

. Diodoran modalities. Philosophical Quarterly, v. 5, n. 20, p. 205-213, 1955. 
QUEVEDO, A. Ens per accidens: contingencia y determinación en Aristóteles. Navarra: Eunsa, 1989.

SCHUHL, P. M. Le Dominateur et les possibles. Paris: P.U.F., 1960.

VIGO, A. Aristóteles: una introducción. Santiago de Chile: IES, 2006.

VUILLEMIN, J. L'argument dominateur in la philosophie analytique. Revue de Métaphysique et de Morale, Paris, v. 84, n. 2, p. 225-257, 1979.

. Nécessité ou contingence. L'aporie de Diodore et les systèmes philosophiques.

Paris: Minuit, 1984.

Recebido: 27/01/2016

Aceito: 19/04/2017 
RÍOS GUTIÉRREZ, I. 